\title{
FORECASTING GOLD PRICE CHANGES BY USING ADAPTIVE NETWORK FUZZY INFERENCE SYSTEM
}

\author{
Abdolreza Yazdani-Chamzini' ${ }^{1}$, Siamak Haji Yakhchali ${ }^{2}$, \\ Diana Volungevičiene ${ }^{3}$, Edmundas Kazimieras Zavadskas ${ }^{4}$ \\ ${ }^{1}$ Young Researchers Club, South Tehran Branch, \\ Islamic Azad University, Tehran, Iran \\ ${ }^{2}$ Department of Industrial Engineering, College of Engineering, Tehran, Iran \\ ${ }^{3}$ Faculty of Business Management, Vilnius Gediminas Technical University, \\ Sauletekio al. 11, LT-10223 Vilnius, Lithuania \\ ${ }^{4}$ Faculty of Civil Engineering, Vilnius Gediminas Technical University, \\ Sauletekio al. 11, LT-10223 Vilnius, Lithuania \\ E-mails:1abdalrezaych@gmail.com; 2yakhchali@yahoo.com; 3dianav@vgtu.lt; \\ ${ }^{4}$ edmundas.zavadskas@vgtu.lt (corresponding author)
}

Received 11 October 2011; accepted 27 March 2012

\begin{abstract}
Developing a precise and accurate model of gold price is critical to assets management because of its unique features. In this paper, adaptive neuro-fuzzy inference system (ANFIS) and artificial neural network (ANN) model have been used for modeling the gold price, and compared with the traditional statistical model of ARIMA (autoregressive integrated moving average). The three performance measures, the coefficient of determination $\left(R^{2}\right)$, root mean squared error (RMSE), mean absolute error (MAE), are utilized to evaluate the performances of different models developed. The results show that the ANFIS model outperforms other models (i.e. ANN and ARIMA model), in terms of different performance criteria during the training and validation phases. Sensitivity analysis showed that the gold price changes are highly dependent upon the values of silver price and oil price.
\end{abstract}

Keywords: forecasting, gold price changes, adaptive network fuzzy inference system.

Reference to this paper should be made as follows: Yazdani-Chamzini, A.; Yakhchali, S. H.; Volungevičienė, D.; Zavadskas, E. K. 2012. Forecasting gold price changes by using adaptive network fuzzy inference system, Journal of Business Economics and Management 13(5): 994-1010.

JEL Classification: C44, C45, E37, E47, E52.

\section{Introduction}

Gold price plays a significant role in economical and monetary systems. The price of gold and other assets are often closely correlated (Corti, Holliday 2010). For example, the link between gold and equities is usually negative, as investors typically transfer money from gold into the safe haven of equities during times of boom and vice versa 
during times of crisis. Whereas, the link between gold and oil is typically positive and a tension can lift both the price of oil and gold.

Accurate forecasting of gold price helps to foresee the circumstances of trends in the future. This provides the useful information for stakeholder to fulfill the essential actions in order to prevent or mitigate risks, which may lead to financial losses or even bankruptcy.

In order to foretell the future price of gold, the forecasting model uses the factors that have a significant effect on determining the gold prices. Several methods have been developed and implemented for the prediction of gold price. The forecasting methods can be classified into three main methods: (i) traditional mathematical model, (ii) artificial intelligence (AI), and (iii) hybrid models.

Traditional mathematical models such as Autoregressive Integrated Moving Average (Parisi et al. 2008), jump and dip diffusion (Shafiee, Topal 2010), and the multi linear regression (Escribano, Granger 1998; Achireko, Ansong 2000; Ismail et al. 2009; Kearney, Lombra 2009) models have been used for gold price forecasting. As well as, artificial intelligence models such as artificial neural networks (ANN) have been developed as a non-linear tool for gold price forecasting (Achireko, Ansong 2000; Parisi et al. 2008; Lineesh et al. 2010).

These studies document the need for a better management of gold selling and investing to reduce risk value. An accurate gold price forecasting model is needed to show the trend of price changes in the futures to carry out appropriate exchanges. Furthermore, it is very difficult to earn a powerful function using traditional mathematical model (Achireko, Ansong 2000), and these models are principally based on some strong assumptions and prior knowledge of input data statistical distributions.

On the other hand, both ANN and fuzzy logic techniques have their advantages and disadvantages. The ANN models are very efficient in adapting and learning, but on the negative side they have the negative attribute of the "black box" (Bilgehan 2011). ANN also have some shortages for addressing issues of uncertainty and imprecision. Fuzzy logic has the ability to express the ambiguity of human thinking and translate expert knowledge into computable numerical data (Mirbagheri, Tagiev 2011). But despite that fuzzy inference system is widely applied, extracting the rules of fuzzy inference system is not easily realized. Whereas a combination of ANN and fuzzy system is called neurofuzzy system has a benefit of two models in a single framework. Neuro-fuzzy systems are able to eliminate the basic problem in fuzzy system design (generating a set of fuzzy if-then rules) by using the learning capability of an ANN for automatic fuzzy if-then rule generation and parameter optimization (Nayak et al. 2004).

There are the different types of fused neuro-fuzzy systems such as Adaptive NeuroFuzzy Inference System (ANFIS), Fuzzy Inference and Neural Network in Fuzzy Inference Software (FINEST), Evolving Fuzzy Neural Network (EFuNN), and Self-Constructing Neural Fuzzy Inference Network (SONFIN). It utilizes a combination of the least squares and back propagation gradient descent method for training fuzzy inference system membership function parameters to emulate a given training data set (Ellithy, Al-Naamany 2000). 
The specific advantages of ANFIS are: (1) ANFIS uses the neural network's ability to classify data and find patterns, (2) It then develop a fuzzy expert system that is more transparent to the user and also less likely to produce memorization errors than a neural network does, and (3) ANFIS keeps the advantages of a fuzzy expert system, while removing (or at least reducing) the need for an expert (Ata, Kocyigit 2010). ANFIS is widely used employed for modeling and forecasting time series by different researchers. It is clear that ANFIS has demonstrated its capabilities and efficiencies as a problemsolving tool.

The main aim of this paper is to investigate the capability of an ANFIS in modeling gold price changes and to evaluate its performance in comparison with ANN and other traditional time series modeling techniques such as ARIMA. Finally, the best fit model is identified according to the performance criteria including coefficient of determination (R2), mean absolute error (MAE), and root mean square error (RMSE).

The rest of the paper is organized as follows: Section 2 is included the literature review and also the methodology of adaptive neural-fuzzy inference system (ANFIS) and describes its structure. Section 3 summarizes artificial neural networks. Section 4 describes the ARIMA model, including the determination of the orders of ARMA model. Section 5 presents the gold price modeling by ANFIS, ANN, and ARIMA models. Section 6 analyzes the performance of the models, including its comparison with other and discusses several practical issues involved in its deployment. Sensitivity analysis is presented in section 7 presents. Finally, the conclusions of the present study are discussed in section 8 .

\section{Adaptive Network-based Fuzzy Inference System (ANFIS)}

Adaptive neural-fuzzy inference system (ANFIS) was initially introduced by Jang (1993). ANFIS is a multilayer feed forward network with a supervised learning scheme, which makes the model of given training data set based on Takagi-Sugeno inference system (Takagi, Sugeno 1985). ANFIS uses a hybrid learning algorithm in order to train the network. According to the unique capability of ANFIS, this technique is applied by different researchers for forecasting time series.

Nayak et al. (2004) developed the application of an ANFIS to hydrologic time series modeling. They demonstrated the potential of an ANFIS model for time series modeling of river flow of Baitarani river basin in Orissa state of India. Ghaffari and Zare (2009) employed soft computing approaches to predict the daily variation of the crude oil price of the West Texas Intermediate. In this paper, the predicted daily oil price variation is compared with the actual daily variation of the oil price and the difference is implemented to activate the learning algorithms.

A comparative analysis of ANFIS and Mamdani fuzzy inference systems (MFIS) methods for prediction of water consumption time series is carried out by Firat et al. (2009). Chen et al. (2010) applied the ANFIS model to forecast the tourist arrivals to Taiwan, they demonstrated according to the mean absolute percentage errors and statistical results, the ANFIS model has better forecasting performance than the fuzzy time series 
model, grey forecasting model and Markov residual modified model. They also used the ANFIS model to forecast the monthly tourist arrivals to Taiwan from Japan, Hong Kong and Macao, and the United States.

Wang et al. (2009) employed autoregressive moving-average (ARMA) models, artificial neural networks (ANNs) approaches, ANFIS techniques, genetic programming (GP) models and support vector machine (SVM) method to forecast monthly discharge time series. The results indicate that the best performance can be obtained by ANFIS, GP and SVM, in terms of different evaluation criteria during the training and validation phases. Chang et al. (2011) developed a new fusion ANFIS model based on an AR model and volatility of the TAIEX (momentum) to forecast stock price problems in Taiwan. Mellit and Kalogirou (2011) demonstrated the application of an ANFIS for modeling and simulation of photovoltaic power supply.

Talebizadeh and Moridnejad (2011) developed various ANN and ANFIS models to forecast the lake level fluctuations in Lake Urmia in northwest of Iran. The results of the ANFIS model are superior to ANN ones in that they are both more accurate and with less uncertainty.

Wan et al. (2011) employed ANFIS to develop models for the prediction of suspended solids (SS) and chemical oxygen demand (COD) removal of a full-scale wastewater treatment plant treating process wastewaters from a paper mill. Yang et al. (2011) proposed an ANFIS model to interpolate the missing and invalid wind data. They provided good descriptions of the ANFIS approach.

Suppose that the rule base contains the following two Sugeno-type fuzzy if-then rules:

$$
\begin{aligned}
& \text { Rule 1: if } x \text { is } \mathrm{A}_{1} \text { and } y \text { is } \mathrm{B}_{1} \text { then } f_{1}=p_{1} x+q_{1} y+r_{1}, \\
& \text { Rule 2: if } x \text { is } \mathrm{A}_{2} \text { and } y \text { is } \mathrm{B}_{2} \text { then } f_{1}=p_{2} x+q_{2} y+r_{2} \text {, }
\end{aligned}
$$

where $x$ and $y$ are the inputs, $\mathrm{A}_{\mathrm{i}}$ and $\mathrm{B}_{\mathrm{i}}$ are the fuzzy sets, $f_{i}$ is the output $\left\{p_{i}, q_{i}, r_{i}\right\}$ are the consequent parameters that are determined during the training process.

The five-layer ANFIS structure consists of fuzzification, inference, normalization, consequent, and output. ANFIS, as presented in Fig. 1, incorporates a five-layer network to implement a Takagi-Sugeno-type fuzzy system.

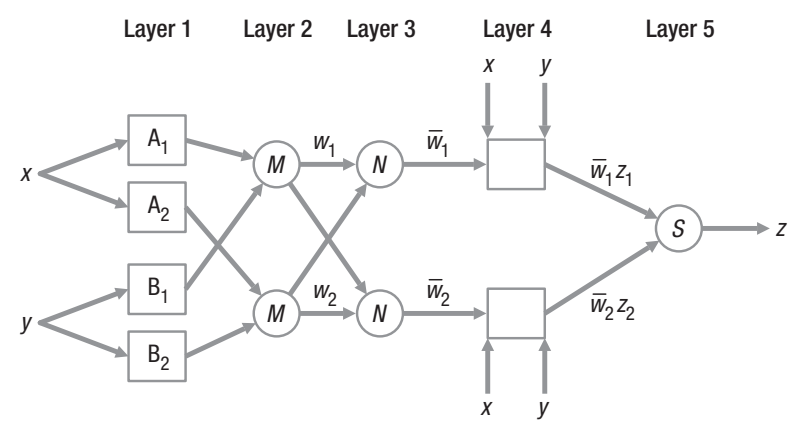

Fig. 1. ANFIS architecture 
The ANFIS structure is described below:

Layer 1: Parameters in the first layer are called premise parameters; each node in this layer generates fuzzy membership grades. let $O_{i j}$ be the output of level $i$, and node $j$ for level one

$$
\begin{aligned}
& O_{1 j}=\mu_{A j}(x) \text { for } j=1,2, \\
& O_{1 j}=\mu_{B j}(x) \text { for } j=3,4,
\end{aligned}
$$

where $\mu_{A i}(x)$ and $\mu_{B i}(x)$ can adopt any fuzzy membership function (MF). In this paper the Gaussian function is used to develop the prediction model. $\mu_{A i}(x)$ is given by:

$$
O_{1 j}=\mu_{A j}(x)=\frac{1}{e^{\frac{(x-c)^{2}}{2 \sigma^{2}}}},
$$

where $c$ is mean of distribution and $\sigma^{2}$ is variance of distribution.

Layer 2: Each node in the second layer calculates the firing strength of each rule via multiplication

$$
O_{2 j}=w_{j}=\mu_{A j}(x) \times \mu_{B j}(x) \text { for } j=1,2 .
$$

Layer 3: Node $i$ in this layer calculates the ratio of the ith rule's firing strength to the sum of all rules' firing strengths. The firing strength in the third layer is normalized $\left(\mathrm{O}_{3 j}\right)$ as:

$$
O_{3 j}=\bar{w}_{j}=\frac{w_{j}}{\left(w_{1}+w_{2}\right)} \text { for } j=1,2 .
$$

Layer 4: In this layer parameters are called consequent parameters and every node computes the contribution of $i$ th rule towards the overall output:

$$
O_{4 j}=\bar{w}_{j} f_{j}=\bar{w}_{j}\left(p_{j} x+q_{j} y+r_{j}\right) \text { for } j=1,2 .
$$

Layer 5: Finally, the single node calculates the overall output as the summation of all incoming signals:

$$
O_{5 j}=\text { overalloutput }=\sum_{j} \bar{w}_{j} f_{j}=\frac{\sum_{j} w_{k} f_{k}}{\sum_{j} w_{k}} \text { for } k=1,2 .
$$

ANFIS uses the hybrid-learning algorithm, consists of the combination of gradient descent, and least-squares methods. The former is employed to determine the nonlinear input parameters and the latter is used to identify the linear output parameters. The main objective of the learning algorithm for ANFIS architecture is to tune all the modifiable parameters in order to match the ANFIS output with the training data.

ANFIS applies two phases, including forward pass and backward pass to recognize the pattern of given data set. The forward pass optimizes the consequent parameters $\left(\mathrm{p}_{\mathrm{i}}, \mathrm{q}_{\mathrm{i}}\right.$, $r_{i}$ ) in levels four and five, while the backward pass optimize the premise parameters of the MFs used as inputs in levels one to three (Atsalakis et al. 2011).

In forward pass, each node output is calculated under the condition that the nonlinear or premise parameters in layer 1 remain fixed. Therefore, the overall output is a lin- 
ear combination of consequent parameters. In backward pass, after subtracting output of layer 5 from the actual output error measure, the error rates propagate backward from output to update the non-linear parameters when the premise parameters are fixed (Ghaffari, Zare 2009). The hybrid algorithm converges much faster than the original pure back propagation algorithm as it reduces the search space dimensions (Jang et al. 1997).

\section{Artificial Neural Networks (ANN)}

ANN technique has emerged as a powerful modeling tool which can be applied for many scientific and/or engineering applications, such as: pattern reorganization, classification, data processing, and process control. ANN technique has some unique futures which distinguish them from other data processing systems include ability to work successfully even when they are party damaged, parallel processing, ability to make generalization, and little susceptibility to errors in data sets (Malinowski, Ziembicki 2006). An artificial neural network simulates the human brain mechanism to implement computing behavior (He, $\mathrm{Xu}$ 2007).

ANN is developed based on biological neural networks, which neurons are the basic building blocks ones. An artificial neuron is a model of a biological neuron. An artificial neuron receives signals from other neurons, gathers these signals, and when fired, transmits a signal to all connected neurons (Engelbrecht 2002). An artificial neuron model is depicted in Fig. 2.

As seen in Fig. 2, $x_{i}(i=1,2, \ldots, \mathrm{n})$ is the input signal of $n$ other neurons to a neuron $j$; $w_{i j}$ is the connection weight between the $i$ th neuron and the neuron $j ; \theta_{j}$ is the activation threshold of the neuron $j ; f$ is the transfer function, and $y_{j}$ is the output of the neuron. $y_{j}$ is calculated through Eq. (7):

$$
y_{i}=f\left(\sum_{i=1}^{n} w_{i j} x_{i}-\theta_{j}\right),
$$

$f$ is generally linear, step, threshold, logarithmic sigmoid (logsig), hyperbolic tangent sigmoid (tansig) functions.

A neural network contains of three layers, including one input layer, several middle layers (hidden layers) and one output layer. It should be noted that there is no theoretical limit on the number of hidden layers but typically there is just one or two (Sumathi, Paneerselvam 2010). Fig. 3 depicts an artificial neural network architecture employed in this study.

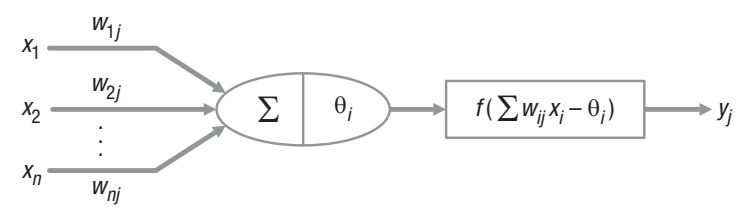

Fig. 2. Artificial neuron model 


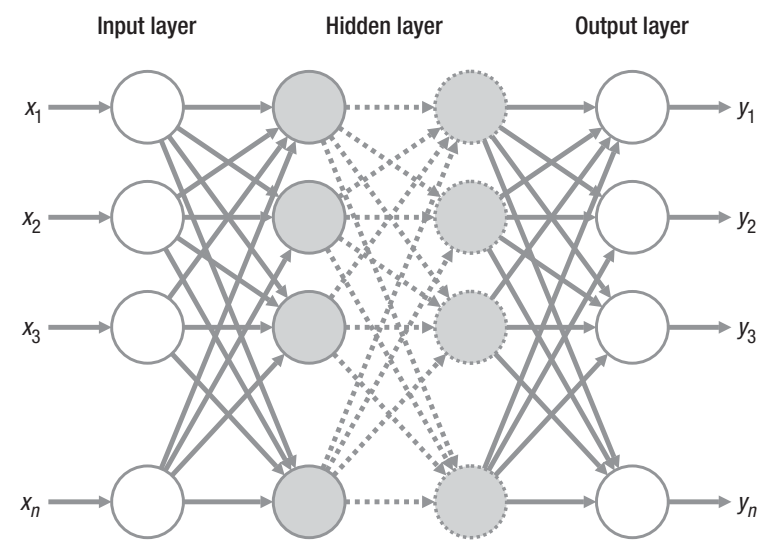

Fig. 3. A typical artificial neural network architecture

In this study a multi-layer feed-forward perceptron (MLP) with a back propagation learning algorithm is employed to model gold price. During the modeling stage, coefficients are adjusted through comparing the model outputs with actual outputs. A fivestep procedure can be described to present the learning process of an ANN as follows:

1. Input-output vectors are randomly selected as training datasets.

2. The structure of network is formed.

3. Network outputs are computed for the selected inputs.

4. Connection weights are adjusted according to performance measure.

5. The process of adjusting the weights is continued until performance measures are satisfied.

\section{ARIMA method}

Box and Jenkins developed a general forecasting methodology for time series generated by a stationary autoregressive moving-average process (Box, Jenkins 1976). In an autoregressive integrated moving average (ARIMA) model, the future value of a variable is assumed to be a linear function of several past observations and random errors. The term integrated indicates the fact that the model is produced by repeated integrating or summing of the ARMA process (Palit, Popovic 2005). The ARIMA model is employed for applications to nonstationary time series that become stationary after their differencing. The general form of the ARIMA model is given by:

$$
\varphi(B) x(t)=\phi(B)(1-B)^{d} x(t) .
$$

The structure of ARIMA model is known as $\operatorname{ARIMA}(p, q, d)$, where $p$ stands for the number of autoregressive parameters, $q$ is the number of moving-average parameters, and $d$ is the number of differencing passes.

The Box and Jenkins methodology for building time series models includes four phases (Box, Jenkins 1976): (1) model identification, (2) model estimation, (3) model validation, and (4) model forecasting. These phases are described in details by Palit and 
Popovic (2005). In order to determine the order of the ARIMA best model, the autocorrelation function $(\mathrm{ACF})$ and the partial ACF (PACF) of the sample data are employed. In this study, selection technique in conjunction with ACF and PACF for estimating the orders of ARMA model is the Akaike information criterion (AIC). This involves choosing the most suitable lags for the AR and MA components, likewise assigning if the variable requires differencing to convert into a stationarity time series.

\section{Modeling of gold price}

The information used in this study includes 220 monthly observations of the gold price per ounce against its affecting parameters from April 1990 to July 2008. The gold price changes during this period are depicted in Fig. 4. In order to develop ANFIS, ANN, and ARIMA models for the gold price, the available data set, which consists of 220 input vectors and their corresponding output vectors from the historical data of gold price, was separated into training and test sets as depicted in Fig. 4. For achieving the aim, 200 observations (from April 1990 to November 2006) are first applied to formulate the model and the last 20 observations (from December 2006 to July 2008) are used to reflect the performance of the different constructed models. Base on the ARIMA model, the past observations of gold price are used in order to formulate the model, and in order to develop ANFIS and ANN models, the affecting parameters on gold price are extracted as described in the following part.

One of the most important steps in developing a successful forecasting model is the selection of the input variables, which determines the architecture of the model. Based on the 'hunches of experts', seven input parameters for the gold price forecasting were identified: USD Index (measures the performance of the United States Dollar against the Canadian Dollar), inflation rate (the United States inflation rates), oil price (West Texas Intermediate Crude Oil Prices), interest rate (the United States interest rates), stock market index (Dow Jones Industrial Average), silver price, and world gold production. The data used in this study were downloaded from several sources from the addresses as presented in Table 1. As shown in Table 1, expect of world gold production, other parameters are monthly. According to the importance of production on the gold price

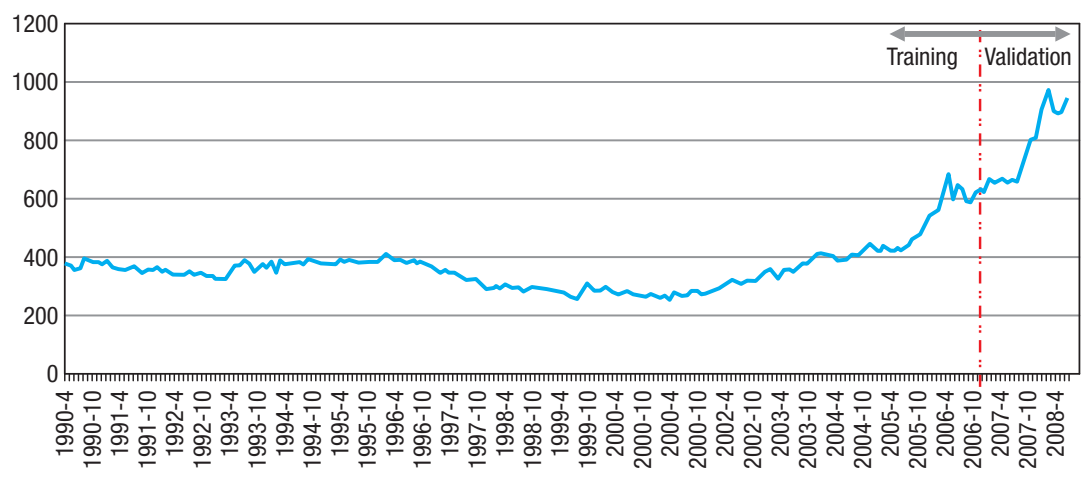

Fig. 4. Gold price changes (data resource: www.kitco.com) 
changes, the authors employed the method of Cubic Spline interpolation (see Ueberhuber 1997), which is a useful technique to interpolate between known data points due to its stable and smooth characteristics, in order to convert annually data into monthly data. The above mentioned models are established as described in the next section.

Table 1. Statistical parameters of each data set

\begin{tabular}{lcccccc}
\hline \multicolumn{1}{c}{ Variable } & Type of data & Maximum & Minimum & Unit & Symbol & \multicolumn{2}{c}{ Resource } \\
\hline Gold price & Monthly & 1134.72 & 256.675 & \$/ounce & G & www.kitco.com \\
\hline Silver price & Monthly & 18.765 & 3.64 & \$/ounce & S & www.kitco.com \\
\hline USD index & Monthly & 1.599 & 0.967 & - & $\mathrm{C}$ & research.stlouisfed.org \\
\hline Oil price & Monthly & 133.93 & 11.28 & \$/barrel & O & www.economagic.com \\
\hline Inflation rate & Monthly & 0.0628 & -0.0209 & - & Inf & www.inflationdata.com \\
\hline Interest rate & Monthly & 8.89 & 2.42 & - & Int & www.econstats.com \\
\hline $\begin{array}{l}\text { stock market } \\
\text { index }\end{array}$ & Monthly & 13930 & 2442.33 & $\$$ & DJ & finance.yahoo.com \\
\hline $\begin{array}{l}\text { World gold } \\
\text { production }\end{array}$ & Annually & 216.95 & 178.195 & Ton & Pg & minerals.usgs.gov \\
\hline
\end{tabular}

ARIMA modal. Using the Eviews package software, the best-fitted model is obtained based on the optimum solution of the parameters (the values of $p, d, q$ ) and the residuals (white noise). The best-fitted model is $\operatorname{ARIMA}(1,1,0)$ as follows:

$$
\widehat{y}_{t}=-1.873+1.008 y_{t-1} \text {. }
$$

ANN model. According to the concepts of ANNs design and using productive algorithm in MATLAB 7.11 package software in order to obtain the optimum network architecture; several network architectures are established to compare the ANNs performance. Before constructing the ANN model, all variables were normalized to the interval of 0 and 1 to provide standardization using Eq. (10):

$$
X_{\text {norm }}=\left(X-X_{\min }\right) /\left(X_{\max }-X_{\min }\right) .
$$

The best fitted network based on the best forecasting accuracy with the test data is contained of seven inputs, twenty four hidden and one output neurons (in abbreviated form, $\left.\mathrm{N}^{(7-24-1)}\right)$. This confirms that simple network structure that has a small number of hidden nodes often works well in out-of-sample forecasting (Zhang 2003; Khashei et al. 2008, 2009; Areekul et al. 2010; Khashei, Bijari 2011). This can be due to the over fitting problem in neural network modeling process that allows the established network to fit the training data well, but poor generalization may happen.

ANFIS model. Similar to the ANN model, using established algorithms in MATLAB 7.11 package software, the best-fitted ANFIS model is selected. As well as, before constructing the ANFIS model, all variables were normalized to the interval of 0 and 1 
through Eq. 10. Based on the ANFIS system, each input parameter might be clustered into several class values to build up fuzzy rules, and each fuzzy rule would be constructed using two or more MFs (Noori et al. 2010).

There are different methods to categorize the input data and make the fuzzy rules. One of the most application methods is subtractive fuzzy clustering (Chiu 1994), which is more used when there are many input variables. For instance, let it be assumed that there are 10 input variables and three MFs for each input variable, the rules will be $3^{10}$ (59049 rules) that lead to the calculation of parameters be long and time-consuming. For this reason, the authors use a subtractive fuzzy clustering to generate the rule base relationship between the input and output variables that each input variable includes three MFs. This method uses the given search radius to measure the density of data points in the feature space (Chiu 1994). A small cluster radius will usually yield many small clusters in the data and leads to generate many rules and a large cluster radius will usually result a few large clusters in the data and causes fewer rules (Tzamos, Sofianos 2006; Gentili 2007; Jelleli, Alimi 2009; Gopalakrishnan et al. 2009).

The most appropriate value for the cluster radius is identified by a trial and error approach by changing the cluster radius value from 0.05 to 0.95 (in increments of 0.05 ). The results of testing data show that the optimum value for the cluster radius is 0.4 and the optimal number of rules for best-fitting model is 7. After forming the initial ANFIS structure, the training stage is accomplished. In order to train the ANFIS model, the number of iteration of hybrid algorithm for correction of model parameters and objective error are taken into account 50 and $10^{-6}$, respectively. Fig. 5 shows that we could have reached the less training error by increasing the number of epochs. After training the ANFIS model, test performance was checked. For achieving the aim, the input vectors from the test data set were presented to the trained network and the forecasted output parameter, were compared with the actual ones for the performance measurement.

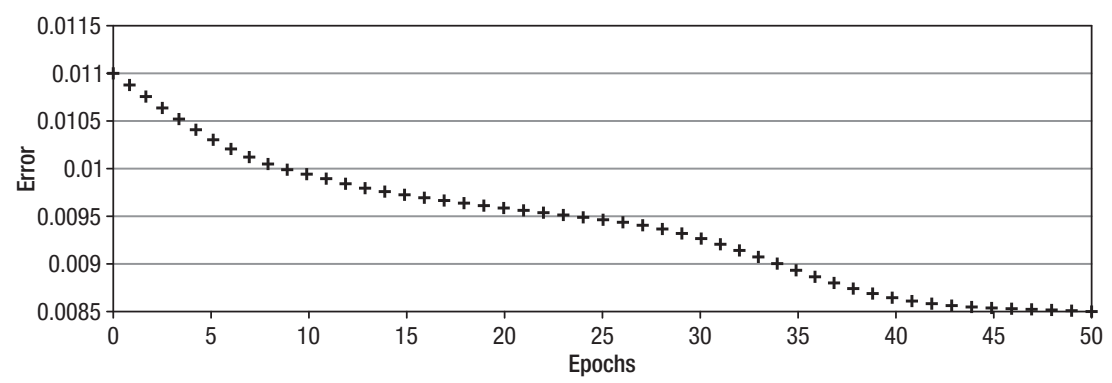

Fig. 5. Trend of errors during epochs

\section{Performance assessment of the models}

In order to generalize the model to unknown outputs, its performance must be tested by comparing outputs estimated by the each model with real outputs. In this paper, the performance of the each model is evaluated by three performance measures: Coefficient of determination $\left(R^{2}\right)$, Mean Absolute Error (MAE), and Root Mean Square Error (RMSE). 
These measures are calculated by following relations:

$$
\begin{gathered}
R^{2}=1-\frac{\sum_{i=1}^{N}\left(A_{i}-P_{i}\right)^{2}}{\sum_{i=1}^{N}\left(A_{i}-\bar{A}_{i}\right)^{2}}, \\
\text { RMSE }=\sqrt{\frac{\sum_{i=1}^{N}\left(A_{i}-P_{i}\right)^{2}}{N},} \\
\text { MAE }=\frac{\sum_{i=1}^{N}\left|A_{i}-P_{i}\right|}{N},
\end{gathered}
$$

where $P_{i}$ is predicted values, $A_{i}$ is observed values, $\bar{A}_{i}$ is the average of observed set, and $N$ is the number of datasets.

$R^{2}$ shows how much of the variability in dependent variable can be explained by independent variable(s). $R^{2}$ is a positive number that can only take values between zero and one. A value for $R^{2}$ close to one shows a good fit of forecasting model and a value close to zero presents a poor fit.

MAE would reflect if the results suffer from a bias between the actual and modeled datasets (Khatibi et al. 2011). RMSE is a used measure in order to calculate the differences between values predicted by a model and the values observed from the thing being modeled. RMSE and MAE are non-negative numbers that for an ideal model can be zero and have no upper bound.

The comparative analysis of testing period performance of the ANFIS, ANN and ARIMA techniques using three global statistical criteria (root mean square error, mean absolute error, and coefficient of determination) has been accomplished and is shown in Table 2. According to the table, for ANFIS, ANN, and ARIMA model, the RMSE values are 29.48, 118.04, and 166.87, and the MAE values are $0.029,0.102$, and 0.144 , and $R^{2}$ values are $0.971,0.967$, and 0.841 , respectively.

For all statistical criteria, the ANFIS model is better than the ANN model, and there are similar conditions to ANN and ARIMA model, i.e. based on all statistical criteria, the ANN model is better than the ARIMA model. This means that ANFIS outperforms ANN and ARIMA and presents the best performance, i.e., the lowest RMSE and MAE and highest $R^{2}$, for the validation periods. The results of the study also indicate that the forecasting capability of the ARIMA model is poor compared with the ANN model in gold price forecasting.

Table 2. Forecasting performance indices of models for gold price

\begin{tabular}{ccccccc}
\hline \multirow{2}{*}{ Model } & \multicolumn{3}{c}{ Training } & \multicolumn{3}{c}{ Validation } \\
\cline { 2 - 7 } & RMSE & MAE & $\mathrm{R}^{2}$ & RMSE & MAE & $\mathrm{R}^{2}$ \\
\hline ARIMA & 14.47 & 0.025 & 0.965 & 166.87 & 0.144 & 0.841 \\
\hline ANN & 13.21 & 0.03 & 0.989 & 118.04 & 0.102 & 0.967 \\
\hline ANFIS & 5.94 & 0.012 & 0.994 & 29.48 & 0.029 & 0.971 \\
\hline
\end{tabular}




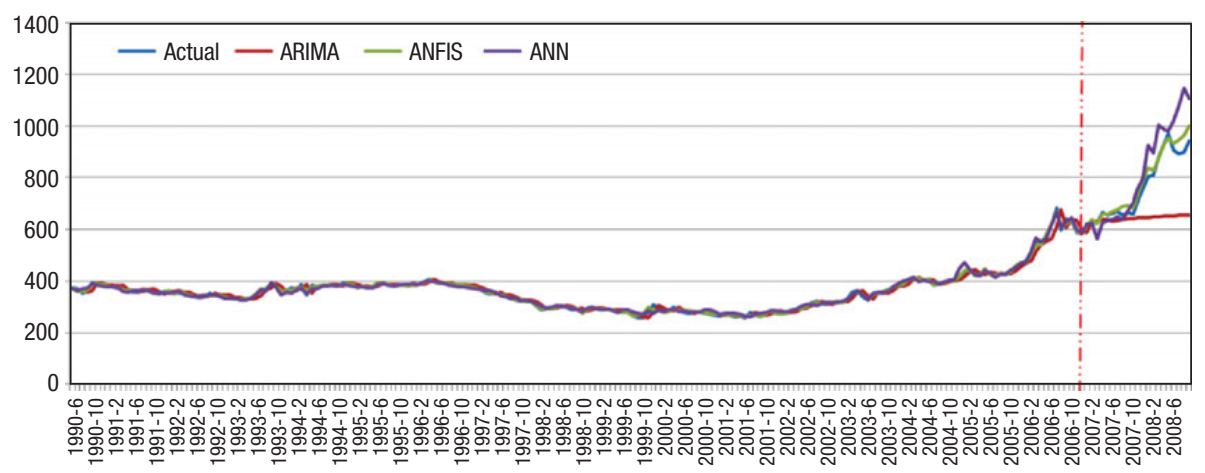

Fig. 6. Actual and forecasted values during training and validation by ARMA, ANN, and ANFIS for gold price

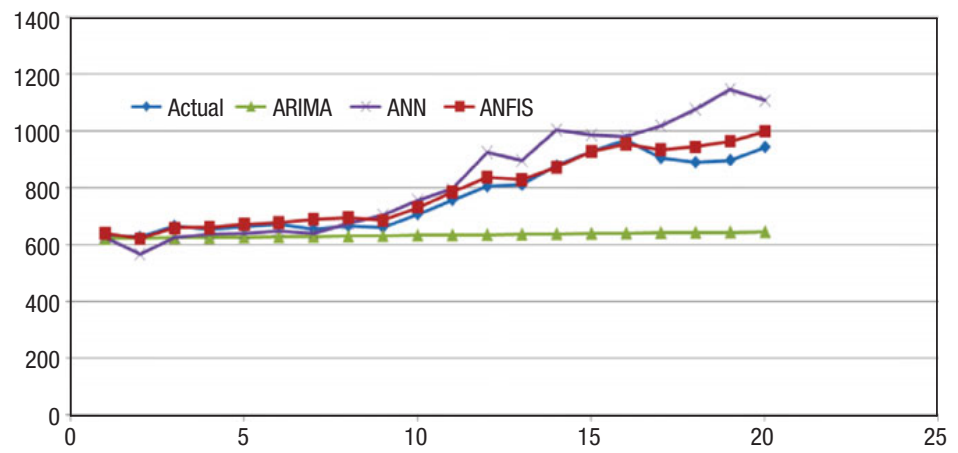

Fig. 7. The variation of the values predicted by ARIMA, ANN, and ANFIS models during validation period, from the actual values

The forecasted value of each model for both validation and training data are plotted in Fig. 6. In addition, the forecasted value of ARIMA, ANN, and ANFIS models for test data are plotted in Fig. 7.

\section{Sensitivity analysis}

Sensitivity analysis is a useful tool in order to determine the relationship between the related parameters. In this paper to identify the most sensitive factors affecting gold price cosine amplitude method (CAM) was employed. This approach is a powerful method in order to implement sensitivity analysis (Ross 2004).

In this method, the degree of sensitivity of each input parameter is assigned by establishing the strength of the relationship $\left(r_{i j}\right)$ between the gold price and input parameter under consideration. The larger the value of CAM becomes, the greater is the effect on the gold price, and the sign of every CAM indicates how the input affects the gold price. If the gold price has no relation with the input, then the values are zero, while the input has a positive effect on the gold price when the values are positive and a negative effect on the gold price when the values are negative. 
Let $n$ be the number of independent variables represented as an array $X=\left\{x_{1}, x_{2}, \ldots\right.$, $\left.x_{n}\right\}$, each of its elements, $\mathrm{x}_{\mathrm{i}}$, in the data array $\mathrm{X}$ is itself a vector of length $m$, and can be expressed as:

$$
X_{i}=\left\{x_{i 1}, x_{i 2}, x_{i 3}, \ldots, x_{i m}\right\} \text {. }
$$

Thus, each of the data pairs can be thought of as a point in $m$ dimensional space, where each point requires $\mathrm{m}$ coordinates for a complete description. Each element of a relation, $r_{i j}$, results from a pairwise comparison of two data samples. The strength of the relationship between the data samples, $x_{i}$ and $x_{j}$, is given by the membership value expressing that strength:

$$
r_{i j}=\frac{\sum_{k=1}^{m} x_{i k} X_{j k}}{\sqrt{\sum_{k=1}^{m} X_{i k}^{2} \sum_{k=1}^{m} X_{j k}^{2}}}, \quad 0 \leq r_{i j} \leq 1 .
$$

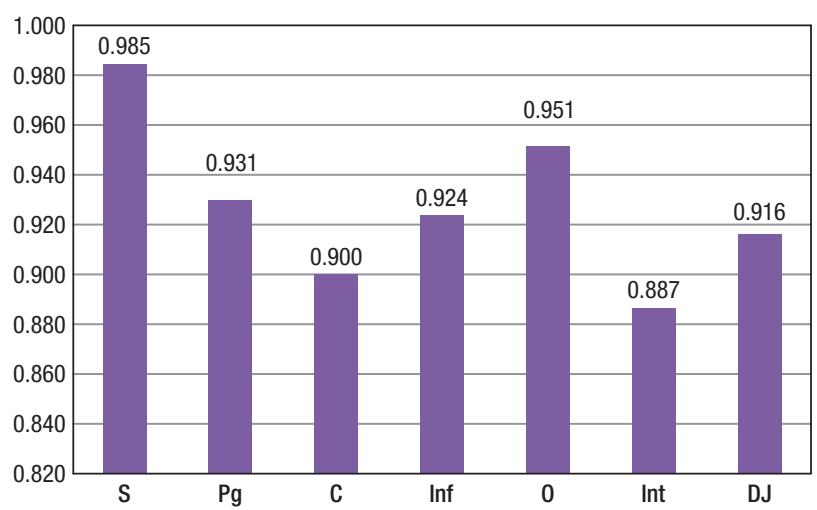

Fig. 8. Sensitivity analysis of input parameters

The strengths of relations ( $r_{i j}$ values) between the gold price and input parameters are depicted in Fig. 8. As shown in Fig. 8, the most effective parameter on the gold price is silver price. It can be resulted due to the substitution relationship between gold and silver prices.

\section{Conclusion}

In this study, the performance of different methods for forecasting the gold price changes was investigated. Because accurate forecasting of gold price changes helps to foresee the circumstances of trends in the future; so that, this provides the useful information for stakeholder to fulfill the appropriate strategies in order to prevent or mitigate risks. The forecasting methods evaluated include the ANN, ANFIS, and ARIMA models. The gold price data from April 1990 to July 2008 were used to develop various models investigated in this study. This comprises 220 input vectors and their corresponding output vectors from the historical data of gold price, which were divided into training and validation sets. Three performance evaluation measures, including MAE, $R^{2}$, and RMSE, are adopted to analyze the performances of various models developed. The 
results show that the ANFIS and ANN methods are powerful tools to model the gold price and can give better forecasting performance than the ARIMA method. The results demonstrate the best performance can be yield by ANFIS in terms of different evaluation criteria during the training and validation phases. The forecasting results of ANN model during the validation phase outperform the ARIMA model. Therefore, the results of the study indicate that ANFIS approach has a high potential in modeling the trend of gold price, and this may provide valuable suggestion for researchers to apply this method for modeling the trend of time series.

\section{Acknowledgement}

The authors would like to acknowledge the financial support of University of Tehran for this research under grant number $03 / 1 / 28433$.

\section{References}

Achireko, P. K.; Ansong, G. 2000. Stochastic model of mineral prices incorporating neural network and regression analysis, The Institution of Mining and Metallurgy (Sect. A: Min. technol.) 109: 49-54.

Areekul, P.; Senjyu, T.; Toyama, H.; Yona, A. 2010. A hybrid ARIMA and neural network model for short-term price forecasting in deregulated market, IEEE Transactions on Power Systems 25(1): 524-530. http://dx.doi.org/10.1109/TPWRS.2009.2036488

Ata, R.; Kocyigit, Y. 2010. An adaptive neuro-fuzzy inference system approach for prediction of tip speed ratio in wind turbines, Expert Systems with Applications 37: 5454-5460.

http://dx.doi.org/10.1016/j.eswa.2010.02.068

Atsalakis, G. S.; Dimitrakakis, E. M.; Zopounidis, C. D. 2011. Elliott Wave Theory and neurofuzzy systems, in stock market prediction: the WASP system, Expert Systems with Applications 38: 9196-9206. http://dx.doi.org/10.1016/j.eswa.2011.01.068

Bilgehan, M. 2011. Comparison of ANFIS and NN models - with a study in critical buckling load estimation, Applied Soft Computing 11: 3779-3791. http://dx.doi.org/10.1016/j.asoc.2011.02.011

Box, P.; Jenkins, G. M. 1976. Time Series Analysis: Forecasting and Control. Holden-day Inc, San Francisco, CA.

Chang, J. R.; Wei, L. Y.; Cheng, Ch. H. 2011. A hybrid ANFIS model based on AR and volatility for TAIEX forecasting, Applied Soft Computing 11: 1388-1395.

http://dx.doi.org/10.1016/j.asoc.2010.04.010

Chen, M. Sh.; Ying, L. Ch.; Pan, M. Ch. 2010. Forecasting tourist arrivals by using the adaptive network-based fuzzy inference system, Expert Systems with Applications 37: 1185-1191.

http://dx.doi.org/10.1016/j.eswa.2009.06.032

Chiu, S. L. 1994. Fuzzy model identification based on cluster estimation, Journal of Intelligent Information Systems 2: 267-278.

Corti, Ch.; Holliday, R. 2010. Gold Science and Applications. Taylor and Francis Group, LLC.

Ellithy, K.; Al-Naamany, A. 2000. A hybrid neuro-fuzzy static var compensator stabilizer for power system damping improvement in the presence of load parameters uncertainty, Electric Power Systems Research 56: 211-223. http://dx.doi.org/10.1016/S0378-7796(00)00125-5

Engelbrecht, A. P. 2002. Computational Intelligence: an Introduction. John Wiley \& Sons, Ltd.

Escribano, A.; Granger, C. W. J. 1998. Investigating the relationship between gold and silver prices, Journal of Forecasting 17: 81-107.

http://dx.doi.org/10.1002/(SICI)1099-131X(199803)17:2<81::AID-FOR680>3.0.CO;2-B 
Firat, M.; Turan, M. E.; Yurdusev, M. A. 2009. Comparative analysis of fuzzy inference systems for water consumption time series prediction, Journal of Hydrology 374: 235-241.

http://dx.doi.org/10.1016/j.jhydrol.2009.06.013

Gentili, P. L. 2007. Boolean and fuzzy logic implemented at the molecular level, Chemical Physics 336: 64-73. http://dx.doi.org/10.1016/j.chemphys.2007.05.013

Ghaffari, A.; Zare, S. 2009. A novel algorithm for prediction of crude oil price variation based on soft computing, Energy Economics 31: 531-536. http://dx.doi.org/10.1016/j.eneco.2009.01.006

Gopalakrishnan, K.; Ceylan, H.; Attoh-Okine, N. O. 2009. Intelligent and Soft Computing in Infrastructure Systems Engineering: Recent Advances. Springer-Verlag Berlin Heidelberg.

http://dx.doi.org/10.1007/978-3-642-04586-8

He, X.; Xu, Sh. 2007. Process Neural Networks Theory and Applications. Springer.

Ismail, Z.; Yahya, A.; Shabri, A. 2009. Forecasting gold prices using multiple linear regression method, American Journal of Applied Sciences 6(8): 1509-1514.

http://dx.doi.org/10.3844/ajassp.2009.1509.1514

Jang, J. 1993. ANFIS: adaptive-network-based fuzzy inference system, IEEE Transactions on Systems, Man, and Cybernetics 23(3): 665-685. http://dx.doi.org/10.1109/21.256541

Jang, J. S.; Sun, C. T.; Mizutani, E. 1997. Neuro-Fuzzy and Soft Computing: a Computational Approach to Learning and Machine Intelligence. Prentice-Hall International, Inc.

Jelleli, T. M.; Alimi, A. M. 2009. On the applicability of the minimal configured hierarchical fuzzy control and its relevance to function approximation, Applied Soft Computing 9(4): 12731284. http://dx.doi.org/10.1016/j.asoc.2009.03.008

Kearney, A. A.; Lombra, R. E. 2009. Gold and platinum: toward solving the price puzzle, The Quarterly Review of Economics and Finance 49: 884-892.

http://dx.doi.org/10.1016/j.qref.2008.08.005

Khashei, M.; Bijari, M. 2011. A novel hybridization of artificial neural networks and ARIMA models for time series forecasting, Applied Soft Computing 11(2): 2664-2675.

http://dx.doi.org/10.1016/j.asoc.2010.10.015

Khashei, M.; Bijari, M.; Ardali, Gh. A. R. 2009. Improvement of auto-regressive integrated moving average models using fuzzy logic and artificial neural networks (ANNs), Neurocomputing 72: 956-967. http://dx.doi.org/10.1016/j.neucom.2008.04.017

Khashei, M.; Hejazi, S. R.; Bijari, M. 2008. A new hybrid artificial neural networks and fuzzy regression model for time series forecasting, Fuzzy Sets and Systems 159(7): 769-786.

http://dx.doi.org/10.1016/j.fss.2007.10.011

Khatibi, R.; Ghorbani, M. A.; Kashani, M. H.; Kisi, O. 2011. Comparison of three artificial intelligence techniques for discharge routing, Journal of Hydrology 403(3-4): 201-212.

http://dx.doi.org/10.1016/j.jhydrol.2011.03.007

Lineesh, M. C.; Minu, K. K.; John, C. J. 2010. Analysis of nonstationary nonlinear economic time series of gold price: a comparative study, International Mathematical Forum 5(34): 1673-1683.

Malinowski, P.; Ziembicki, P. 2006. Analysis of district heating network monitoring by neural networks classification, Journal of Civil Engineering and Management 12(1): 21-28.

Mellit, A.; Kalogirou, S. A. 2011. ANFIS-based modelling for photovoltaic power supply system: a case study, Renewable Energy 36: 250-258. http://dx.doi.org/10.1016/j.renene.2010.06.028 
Mirbagheri, M.; Tagiev, N. 2011. Analyzing economic structure and comparing the results of the predicted economic growth based on solow, fuzzy-logic and neural-fuzzy models, Technological and Economic Development of Economy 17(1): 101-115.

http://dx.doi.org/10.3846/13928619.2011.554201

Nayak, P. C.; Sudheer, K. P.; Rangan, D. M.; Ramasastri, K. S. 2004. A neuro-fuzzy computing technique for modeling hydrological time series, Journal of Hydrology 291: 52-66.

http://dx.doi.org/10.1016/j.jhydrol.2003.12.010

Noori, R.; Hoshyaripour, Gh.; Ashrafi, Kh.; Araabi, B. N. 2010. Uncertainty analysis of developed ANN and ANFIS models in prediction of carbon monoxide daily concentration, Atmospheric Environment 44: 476-482. http://dx.doi.org/10.1016/j.atmosenv.2009.11.005

Palit, A. K.; Popovic, D. 2005. Computational Intelligence in Time Series Forecasting: Theory and Engineering Applications. Springer-Verlag London Limited.

Parisi, A.; Parisi, F.; Díaz, D. 2008. Forecasting gold price changes: Rolling and recursive neural network models, Journal of Multination Financial Management 18: 477-487.

http://dx.doi.org/10.1016/j.mulfin.2007.12.002

Ross, T. J. 2004. Fuzzy Logic with Engineering Applications. Second edition. John Wiley \& Sons Ltd.

Shafiee, Sh.; Topal, E. 2010. An overview of global gold market and gold price forecasting, Resources Policy 35: 178-189. http://dx.doi.org/10.1016/j.resourpol.2010.05.004

Sumathi, S.; Paneerselvam, S. 2010. Computational Intelligence Paradigms: Theory and Applications Using MATLAB. Taylor and Francis Group, LLC.

Takagi, T.; Sugeno, M. 1985. Fuzzy identification of systems and its application to modeling and control, IEEE Transactions on Systems, Man, and Cybernetics 15: 116-132.

Talebizadeh, M.; Moridnejad, A. 2011. Uncertainty analysis for the forecast of lake level fluctuations using ensembles of ANN and ANFIS models, Expert Systems with Applications 38: 4126-4135. http://dx.doi.org/10.1016/j.eswa.2010.09.075

Tzamos, S.; Sofianos, A. I. 2006. Extending the Q system's prediction of support in tunnels employing fuzzy logic and extra parameters, International Journal of Rock Mechanics and Mining Sciences 43(6): 938-949. http://dx.doi.org/10.1016/j.ijrmms.2006.02.002

Ueberhuber, Ch. W. 1997. Numerical Computation: Methods, Software, and Analysis. Vol. 1. Springer-Verlag Berlin Heidelberg.

Wan, J.; Huang, M.; Ma, Y.; Guo, W.; Wang, Y.; Zhang, H.; Li, W.; Sun, X. 2011. Prediction of effluent quality of a paper mill wastewater treatment using an adaptive network-based fuzzy inference system, Applied Soft Computing 11: 3238-3246.

http://dx.doi.org/10.1016/j.asoc.2010.12.026

Wang, W. Ch.; Chau, K. W.; Cheng, Ch. T.; Qiu, L. 2009. A comparison of performance of several artificial intelligence methods for forecasting monthly discharge time series, Journal of Hydrology 374: 294-306. http://dx.doi.org/10.1016/j.jhydrol.2009.06.019

Yang, Z.; Liu, Y.; Li, Ch. 2011. Interpolation of missing wind data based on ANFIS, Renewable Energy 36: 993-998. http://dx.doi.org/10.1016/j.renene.2010.08.033

Zhang, G. P. 2003. Time series forecasting using a hybrid ARIMA and neural network model, Neurocomputing 50: 159-175. http://dx.doi.org/10.1016/S0925-2312(01)00702-0 
Abdolreza YAZDANI-CHAMZINI. Master of Science in the Dept of Strategic Management, research assistant of Fateh Reaserch Group, Tehran-Iran. Author of more than 20 research papers. In 2011 he graduated from the Science and Engineering Faculty at Tarbiat Modares University, Tehran-Iran. His research interests include decision making, forecasting, modeling, and optimization.

Siamak Haji YAKHCHALI is Assistant Professor of Industrial Engineering Department \& Director of MBA programmers, Faculty of Engineering, University of Tehran, Tehran, Iran. He has a PhD in Industrial Engineering in the field of Project management and scheduling under uncertainty. He is the author of more than 25 research papers. His area of expertise is in Project Management with interest in Strategic Management, Decision Making theory, and Fuzzy Logic.

Diana VOLUNGEVIČIENE் is Assistant Professor of the Department International Economics and Business Management at Vilnius Gediminas Technical University, Vilnius, Lithuania. She has a Geodesist engineer (VTU), 1992 and Masters of Civil engineer (VGTU), 1998. She is the author and co-author of more than 10 papers. Research interests are: Innovation Management, International Economics, Regional Economics, Economic Geography, and GIS Application.

Edmundas Kazimieras ZAVADSKAS is head of the Research Institute of Internet and Intelligent Technologies and head of the Department of Construction Technology and Management at Vilnius Gediminas Technical University, Vilnius, Lithuania. He has a PhD in building structures (1973) and DrSc (1987) in building technology and management. He is a member of the Lithuanian and several foreign Academies of Sciences. He is Doctore Honoris Causa at Poznan, Saint-Petersburg, and Kiev universities. He is a member of international organizations and has been a member of steering and programme committees at many international conferences. E. K. Zavadskas is a member of editorial boards of several research journals. He is author and co-author of more than 400 papers and a number of monographs. Research interests are: building technology and management, decision-making theory, automation in design and decision support systems. 